\title{
A GESTÃO PARTICIPATIVA: A POSTURA DO GESTOR ESCOLAR MEDIADOR DO PROCESSO DE TOMADA DE DECISÃO
}

\section{ARTIGO ORIGINAL}

RODRIGUES, Emanoel Márcio da Silva ${ }^{1}$

BRAGA, Maria de Fátima Oliveria ${ }^{2}$

SANTOS, Maria Diana Bruno dos ${ }^{3}$

BRITO, Suely de Oliveira Pereira ${ }^{4}$

MOTA, Francisca Yara de Oliveira ${ }^{5}$

CARNEIRO, Cleide ${ }^{6}$

GONDIM, Terezinha de Jesus Peres ${ }^{7}$

RODRIGUES, Emanoel Márcio da Silva. Et al. A gestão participativa: A postura do gestor escolar mediador do processo de tomada de decisão. Revista Científica Multidisciplinar Núcleo do Conhecimento. Ano 05, Ed. 01, Vol. 07, pp. 107-133.

\footnotetext{
${ }^{1}$ Mestrado Profissional Ensino na Saúde (CMEPES) pela Universidade Estadual do Ceará (UECE).

2 Especialização em Gestão Escolar pela Universidade Federal do Ceará (UFC).

${ }^{3}$ Especialização em Psicopedagogia pela Universidade Estadual Vale do Acaraú (UVA).

${ }^{4}$ Graduada em Pedagogia pela Universidade Estadual Vale do Acaraú (UVA).

${ }^{5}$ Especialização em Psicopedagogia pela Faculdade Aldeia de Carapicuíba (FALC).

${ }^{6}$ Doutorado em Serviço Social pela Universidade Estadual Paulista Júlio de Mesquita Filho - UNESP.

${ }^{7}$ Mestrado Profissional em Políticas Públicas e Gestão da Educação Superior pela Universidade Federal do Ceará (UFC).
} 
Janeiro

de

2020.

ISSN:

2448-0959,

Link

de

acesso: https://www.nucleodoconhecimento.com.br/educacao/gestao-participativa

\section{RESUMO}

Este estudo tem como objetivo compreender a postura dos gestores municipais no processo de tomada de decisão, visando o ato de mediação para a construção de práticas democráticas na gestão participativa. Portanto, ao ressaltar o processo de tomada de decisão como um percurso essencial nas práticas educativas, os gestores devem planejar encontros para debates acerca das metas a serem implementadas na instituição educacional. O caminho a ser percorrido surge por meio da problemática da investigação: Qual tipo de postura o gestor escolar deverá se apropriar para tornarse um mediador interno, através da tomada de decisão considerando a ação um processo contínuo de construção da gestão democrática e participativa? Sendo, nessa perspectiva, muito viável ao gerenciamento da unidade escolar de maneira transparente e participativa, entendendo que a escola não se encontra isolada da sistemática da sociedade contemporânea, do contexto geográfico, político e sociocultural. Dessa maneira, o gestor escolar em sua atuação tem uma importante função a exercer, sua postura precisa assegurar que à escola seja um espaço democrático e participativo no contexto contemporâneo. A metodologia do presente trabalho optou por utilizar a metodologia da pesquisa de campo com abordagem qualitativa, seguida de uma amostra de profissionais de uma escola pública de Fortaleza-CE. Foi utilizada a entrevista como instrumento para colheita e análise dos dados copilados.

Palavras-chave: Gestão escolar, gestão participativa, tomada de decisão.

\section{INTRODUÇÃO}

Esta pesquisa busca contribuir com a reflexão dos profissionais da educação no que diz respeito à responsabilidade e comprometimento dos gestores educacionais acerca do processo de tomada de decisão. Sendo esse percurso uma construção da autonomia adquirida na rotina de encontros socializadores vinculando o poder de 
decisão atribuído à comunidade escolar, democratizando a participação de todos os seguimentos que formam a instituição e suas adjacências, pois, o gestor deve ser um mediador com intencionalidade positiva entre trabalhadores da educação, pais e alunos.

Portanto, sua postura será o foco primordial para se compreender melhor a atuação desse profissional engajado nos mecanismos culturais, pedagógicos, administrativos, financeiros, humanos, materiais e organizacionais contidos numa escola. $\mathrm{Na}$ concepção de Lück (2017a) a gestão precisa mobilizar a comunidade escolar para assegurar que todos desenvolvam as competências e a autonomia dos sujeitos sobre decidir, projetar metas e coordenar pessoas com o objetivo de solucionar problemas e garantir a aprendizagem. A participação possibilita que os atores educacionais se tornem protagonistas no planejamento das ações pedagógicas que projetem uma educação de qualidade.

É nessa constante busca pelo entendimento da real estruturação da escola pública democrática e participativa que o gestor precisa se qualificar para que possa desempenhar seu papel de forma clara e precisa, mediante o processo de tomada de decisão. Ressalta-se que todos os sujeitos envolvidos fazem parte do processo de escolha, à medida que se utiliza dos mecanismos de estruturação da identidade e dos objetivos organizacionais dessa escola. Para Paiva (2016) uma instituição bem organizada fomenta estratégias eficazes na resolução das dificuldades de aprendizagem, obtendo resultados positivos por meio de um acompanhamento pedagógico constante.

Diante dessa perspectiva que se analisará o gerenciamento da instituição educacional sob a ótica do gestor escolar, portanto, ao longo desta pesquisa, se buscará responder ao seguinte questionamento: Qual tipo de postura o gestor escolar deverá se apropriar para tornar-se um mediador interno, através da tomada de decisão considerando a ação um processo contínuo de construção da gestão democrática e participativa? A participação dos profissionais da educação conduz a uma reflexão crítica sobre as dificuldades em tempo real a respeito do cotidiano do espaço educativo, sabendo que 
eles estão inseridos no cenário educacional, em que influenciam diretamente ou indiretamente os rumos a serem tomados pelos envolvidos.

Ressaltando que precisamos ter direito a voz, no que diz respeito ao processo de tomada de decisão e na construção coletiva da identidade da instituição educacional, valorando suas singularidades e territorialização, pois o gestor precisa considerar que o silêncio desses técnicos também pode interferir no processo de crescimento desta, então nada melhor que oportunizar que eles possam ser coparticipantes do sucesso da escola.

Diante disso, uma gestão participativa envolve todos os sujeitos na projeção das metas a ser executada, a comunidade escolar quando se engaja na tomada de decisão assegura que as ações pedagógicas pleiteadas no ambiente educacional partam do princípio democrático. O envolvimento da população não pode ser assegurado só com a inclusão, mas com um planejamento baseado em evidências que possam nortear os objetivos e as respectivas metas (PAIVA, 2016).

Toda pesquisa tem uma finalidade um norte a ser percorrido e um rumo a ser explorado, assim, os objetivos do trabalho são direcionados pelo geral e específicos, cada um com suas particularidades e interligados entre si. O objetivo geral da pesquisa é: Compreender a postura dos gestores municipais no processo de tomada de decisão, visando o processo de mediação para a construção de práticas democráticas na gestão participativa. Seguido pelos objetivos específicos que norteiam o desfecho de toda pesquisa: a) Identificar a interação existente entre a gestão participativa e processo de tomada de decisão em âmbito institucional; b) Verificar como os gestores atuam executando os mecanismos de mediação e liderança no processo de disseminação da prática da gestão participativa e refletir sobre a opinião de gestores escolares e professores de uma instituição pública do município de Fortaleza-CE.

Dessa maneira, todo o contexto da pesquisa aqui descrito está vinculada com a gestão da instituição educacional e seus respectivos aspectos atuais, fornecendo orientações 
teóricas e práticas para um bom entendimento da organização da gestão democrática e participativa no âmbito escolar.

Segundo Lück (2017a) é imprescindível que o gestor escolar consiga gerenciar e coordenar à demanda institucional, oferecendo à comunidade escolar a oportunidade de discutir sobre os elementos que podem auxiliar na internalização dos saberes. Conhecer as diretrizes que norteiam o seu trabalho na esfera federal, estadual e municipal é primordial para implementarmos ações pedagógicas que estimulem a participação na criação de projetos de trabalho significativos.

As mudanças acontecem e continuam ocorrendo no contexto cearense como as diversas metodologias no intuito de aprimorar e democratizar o processo de gestão escolar e ensino, mostrando nos últimos anos debates nesse campo, esse trajeto em andamento constante, inclui os processos de tomadas de decisões, os mecanismos para a escolha dos procedimentos a serem usados e outros instrumentos envolvidos no âmbito das instituições de ensino, lembrando que atualmente os municípios cearenses já trazem algumas discussões acerca do modelo de gestão atual, claro que muita ação ainda precisa ser aprimorada.

É fundamental que o compromisso com a prática democrática no âmbito escolar seja um princípio assegurado pelos gestores escolares, a busca por soluções de problemas pedagógicos enfrentados é uma das atribuições de um gestor líder. A participação é uma maneira de compartilhar e observar pontos de vistas que efetivem as atividades que resultarão em um retorno na aprendizagem, assim como, nas avaliações internas e externas (LÜCK, 2017b).

Para se chegar a um conhecimento prático, este trabalho se constituiu por uma organização apresentada nos seguintes tópicos: I) Gestão participativa: um olhar acerca do processo de liderança nas tomadas de decisões em âmbito escolar; II) O gestor escolar e a prática da gestão democrática e participativa no contexto atual; III) A gestão escolar participativa sob a ótica dos gestores e docentes. Portanto, sua estruturação nos permite buscar entender a real situação dos gestores engajados em instituições de ensino, permitindo assim, uma reflexão sobre a postura desse 
profissional, liderança, processo de tomada de decisão, formação inicial e a mediação em âmbito institucional interno.

Por fim, as referências bibliográficas serão direcionadas a escola e a gestão participativa, autonomia da instituição escolar para que aconteça o desenvolvimento da rotina democrática e a implementação dos trabalhos realizados pela escola.

Dessa forma, pode gerar nos trabalhos em instituição de ensino uma análise reflexiva acerca do papel do gestor nas atividades educacionais realizados em âmbito interno e por seus respectivos profissionais. Ler, refletir e analisar é importantíssimo em uma rotina educacional, pois, o ato de registrar a prática docente é de fundamental importância para nortear o (re) planejamento de novos instrumentos de qualidade, sendo essa é claro uma função do gestor exteriorizando sua práxis educacional no sentido de construção do espírito de liderança, mediando através de ações positivas no processo de tomada de decisão.

\section{GESTÃO PARTICIPATIVA: UM OLHAR ACERCA DO PROCESSO DE LIDERANÇA NAS TOMADAS DE DECISÕES EM ÂMBITO ESCOLAR}

A gestão participativa é algo que advêm de um poder de decisão democrática, coletivo e escolhido de forma abrangente pensando no bem comum. Portanto, esse processo de gerenciamento requer um poder de liderança, pois, um gestor deve participar de maneira ativa e coesa de todos os momentos de escolha da instituição. Participação essa que deve ser compreendida como um modelo de gestão democrática e que leve em consideração todas as opiniões acerca do futuro e dos projetos propostos para melhoria da instituição.

Então, os profissionais da educação devem entender que não se pode pensar em participação coletiva nas tomadas de decisões, ocasionando democracia, sem refletir sobre autonomia da instituição. Esse mecanismo de autonomia é um processo dinâmico e complexo, contudo extremamente necessário para o desenvolvimento e aperfeiçoamento das instituições. Dessa forma, compreender que a liberdade e independência são princípios que fundamentam os universos de igualdade de 
oportunidades das tomadas de decisões, podendo assim, ocasionar o melhoramento e desenvolvimento positivo da instituição.

Para Oliveira (2010) todos os cidadãos necessitam conhecer os mecanismos utilizados para a tomada de decisão, sendo este uma ferramenta que perpasse a transparência, deixando evidentes as escolhas realizadas, as garantias de fiscalização das ações e um respeito mútuo ao pluralismo de opiniões surgidas no espaço da instituição.

Assim, a gestão educacional considerada como democrática, tem sua fundamentação no princípio a legislação educacional brasileira, sendo considerada obrigatória sua existência nas instituições de ensino atuais. A sociedade deve entender gestão educacional democrática como, de acordo com Oliveira:

[...] forma não violenta que faz com que a comunidade educacional se capacite para levar a termo um projeto pedagógico de qualidade e possa também gerar "cidadãos ativos" que participem da sociedade como profissionais compromissados e não se ausentem de ações organizadas que questionam a invisibilidade do poder (2010; p. 17).

Entendem aqui claramente que esse processo no âmbito escolar inicia-se com a elaboração do projeto político pedagógico, onde se deve reunir a todos, analisar argumentos, conhecer a história enquanto instituição, a política, construir a filosofia e missão social, enfim, diversos mecanismos que exigem o coletivismo de todos que compõem a instituição escolar.

Assim, a instituição educacional não pode perder sua autonomia, sua capacidade de construir metas ou ações que venham melhorar sua estrutura física ou mesmo curricular, o processo avaliativo de suas ações requer saberes que construídos ao longo dos anos formados por um fluxograma de possíveis possibilidades de ações a serem melhoradas ou criadas em prol de um atendimento de qualidade.

Ao passo que a instituição escolar adquiriu essa autonomia nos democratizamos em uma construção coletiva, melhorando o processo de tomada de decisão e mediando 
as ações a serem desempenhadas. Segundo Gadotti: "Educar significa, então, capacitar, potencializar, para que o educando seja capaz de buscar a resposta do que pergunta, significa formar para a autonomia" (GADOTTI, 2010; p.13).

Essa atitude de democratizar o processo educacional o tornando dinâmico e participativo nas escolhas feitas pelo grupo possibilita para o gestor escolar, uma realidade de co-responsabilidades, pois, se todos foram de comum acordo no momento das decisões, também se têm a corroboração de todos na execução das ações pedagógicas que estão asseguradas no plano de metas da instituição.

O gestor nesse caso fará um papel importantíssimo de organizador das ideias e pautará atribuições necessárias ao cumprimento de tais medidas, sendo ele um elo de mediação positiva entre gerenciamento externo educacional e ambiente interno com suas respectivas peculiaridades preexistente.

Dessa maneira, não teríamos a capacidade de acreditar em uma autonomia da instituição educacional sem o pleno reconhecimento da liberdade dos sujeitos que a compõem. Portanto, essas atitudes de democracia que devem gerar ambientes autônomos e coletivos resultam do direcionamento das tomadas de decisões de forma conjunta, sendo necessário o respeito para ouvir e saber mediar os fatos ocorridos. Não se pode classificar a existência de uma autonomia da instituição educacional em abstrato, fora do direcionamento da autonomia organizada dos seus membros, advoga Ferreira:

O que está em causa não é "conceder maior ou menor autonomia às escolas", mas sim reconhecer a autonomia da escola como um valor intrínseco à sua organização, e utilizar essa autonomia em benefício das aprendizagens dos alunos (FERREIRA, 2011; p.25).

Concomitantemente, a classificação da autonomia da escola é um processo contínuo que garante a instituição educacional um poder de liderança na tomada de decisão, levando em consideração suas particularidades e conquistas ao longo dos anos, pensado claramente em trabalhar os pontos fracos e fortalecer os fortes ali existentes. 
O gestor mediador do processo é um verdadeiro líder no espaço em que atua, fazendo com que os demais profissionais tenham na figura dele confiança e respeito para poderem exercer a democracia no cenário da educação.

O cenário contemporâneo da educação no Ceará e porque não falar no território brasileiro como quase totalidade é um momento de transição ainda recente, no que se refere à democracia, principalmente a política de resultados no espaço escolar. As pessoas às vezes confundem democracia com atos que na verdade não condizem com a instância da construção coletiva, como o respeito às diversas opiniões ou saberes e, assim, continua-se a produzir uma cultura de desigualdade e desumanidade.

Ser um líder é saber ouvir, assimilar o que é necessário e útil a maioria, e conduzir os espaços coletivos de forma organizada e harmoniosa, gerando entre os membros da comunidade envolvimento e participação no processo contínuo de tomada de decisão.

Contudo deve-se reconhecer que o poder de decisão deve advir da escola com seus representantes locais, pessoas que conheçam seus problemas e seus pontos fortes, membros que vejam na escola um lugar de melhorias sociais e um universo de construção da autonomia e da participação. Afirma Ferreira que:

[...] Em determinadas situações e mediante certas condições, os órgãos representativos das escolas (reunindo professores, outros funcionários, alunos, pais e outros elementos da comunidade) podem gerir certos recursos melhor que a administração central ou regional (FERREIRA, $2011 ;$ p.27).

O gestor escolar líder tem um papel central nesse espaço comunicativo de mediação de opiniões, ele necessita compreender que a assimilação dessas múltiplas falas advém de uma discussão coletiva e que todos os envolvidos nessa dinâmica social almejam o enriquecimento e o fortalecimento da escola.

Para Lück (2010) diversos estudiosos revelam em suas pesquisas literárias alguns elementos fundamentais e comuns para a atuação da prática de liderança, dando 
significado a estruturação desse personagem tão importante na dinâmica do gerenciamento de uma organização. Portanto, os elementos fundamentais são os seguintes: i) Influência sobre pessoas, a partir de sua motivação para uma atividade; ii) Propósito claros de orientação, assumidos por essas pessoas; iii) Processos sociais dinâmicos, interativos e participativos; iv) Modelagem de valores educacionais elevados; v) Orientação para o desenvolvimento e aprendizagem contínuos.

Assim, compreende-se que um líder tem um papel de extrema importância no convencimento de um grupo, que seu poder de conduzir os trabalhos influência de maneira estimulante no processo de tomada de decisão. Então, a liderança é exercida com a influência que se concretiza com a gestão de pessoas, considerando dessa maneira os esforços do grupo e seus respectivos talentos ou habilidades. Levando-se em conta o conhecimento sobre a organização educacional e seus respectivos projetos de trabalho, no qual asseguram a oferta de uma educação de qualidade (LÜCK, 2010).

Dessa forma, a educação pode contribuir de maneira decisória na sustentabilidade da sociedade cuja está inserida respectivamente. Segundo Campos (2010) a educação tem um papel importantíssimo nesse cenário de construção do espaço participativo e democrático, portanto, entende-se aqui que:

[...] O papel da educação poderia se constituir como uma categoria transversal no eixo de prioridade para melhoria das condições de vida do povo, ao lado da prioridade com a opção pela saúde e de infraestrutura da mais alta qualidade com o aprofundamento da democracia [...] (2010; p.25).

Está claro que a instituição educacional tem uma missão importante no processo de estruturar seus nortes e fundamentar sua prática, voltada as suas necessidades locais, concomitantemente, elevar o nível cultural e de letramento da sociedade, sendo um ponto positivo e de referência no processo contínuo de educar. Seu papel porventura não se restringe apenas educar ou de cuidar de uma população, mas o de democratizar todo o processo de escolha e melhoramento de suas atividades internas, 
levando a conhecer a gestão maior que é o Estado, ou gestão externa, suas metas e conquista ao longo dos anos.

Para Campos (2010) a compreensão existente entre educação e sociedade, necessita do aprimoramento da visão analítico-reflexivo a respeito das diversas situações e contradições da instituição educacional no âmbito social. A instituição educacional atualmente sofre muita influência da sociedade capitalista advinda das relações de poder hegemônicas da sociedade contemporânea. De acordo com Campos:

Talvez o grave problema da educação no Brasil não esteja na escola em si, mas no seu entorno. A pobreza e a miséria que marcam a vida do povo marcam também a escola. Ela é a expressão dos conflitos de interesses que movem as relações sociais na sociedade capitalista (2010; p.27).

Contudo, essa mesma luta de classes tem que levar em conta a voz daqueles que enfrentam as dificuldades de perto no cotidiano. A escola tem que proporcionar a democracia, promovendo momentos onde o cidadão que dela participa de forma "ativa" no processo de tomada de decisão seja verdadeiramente considerado, pois, sua missão é a de atender uma demanda de metas que assegurem o melhoramento institucional e conduza a resultados significativos de aprendizagem.

Deve-se entender que a participação dos membros que compõem a comunidade escolar precisa ser interpretada como algo dinâmico e interativo que perpassa somente a democrática tomada de decisão, uma vez que isso se dá pelo pleno convívio dos momentos realizados no ambiente educacional, sendo esse mecanismo algo mais amplo, como o enfretamento dos desafios que são muitos se tratando do ambiente educacional e toda sua complexidade, complementado com a construção de uma identidade positiva no universo social (LÜCK, 2010).

Ainda segundo Lück (2010) a participação em seu sentido amplo é classificada pela mobilização efetiva dos esforços individuais para vencer atitudes de acomodação, de alienação, de marginalidade, e reversão desses mecanismos negativos de 
comportamento totalmente individuais, trocando isso pela construção de um trabalho de equipe, estimulando a construção de metas que serão de cunho coletivo e de responsabilidades assumidas por todos os membros.

A importância da democracia na propedêutica da participação coletiva, entendendo que esse processo de construção contínua é um mecanismo que necessita de introdução e treinamento porque mesmo os momentos ditos democráticos exigem debates para as melhores escolhas em prol de melhoria da educação.

No próximo tópico discutir-se-á sobre a atuação do gestor escolar propriamente dito e os elementos essenciais a organização do papel de líder na desmistificação da inclusão de uma gestão participativa.

\section{O GESTOR ESCOLAR E A PRÁTICA DA GESTÃO DEMOCRÁTICA E PARTICIPATIVA NO CONTEXTO ATUAL}

O profissional da educação tem como mérito a liderança comunicativa no processo de tomada de decisão, tendo sempre a missão de desenvolver um trabalho voltado para a aquisição do conhecimento e prática da democracia. Sabendo que a instituição escolar é um local de inúmeras ideias precisa-se entender a dinâmica social que a circunda, no pleno intuito de consolidar um ambiente extremamente participativo no que se refere às tomadas de decisões e as metas a serem estabelecidas.

O coletivo vem aqui influenciar de maneira primordial, todos os objetivos pretendidos devem sempre passar pela análise do grupo que constitui a comunidade escolar, compartilhando todos os pontos almejados e suas estratégias humanas e financeiras para serem atingidos respectivamente. A transparência é algo que deve permear o âmbito do gerenciamento educacional, pois é por meio dela que reconhecem uma instituição pública como elo de democracia e participação no contexto de gestão contemporânea.

Os mecanismos de participação são resultados da mobilização e do envolvimento de todos no partilhamento do poder e no compromisso com 
o aprendizado político desse processo que se efetiva no exercício de construção cotidiana de várias formas de participação (BRASIL, 2005, p.47).

Assim, compreende-se que o gestor escolar tem essa grande missão em sua atuação profissional que é a de servir de "ponte" no processo contínuo de tomada de decisão, as escolhas devem ser de marco coletivo, visando sempre o bem comum da instituição e do serviço que oferece a comunidade. Por meio desse contexto de compartilhar opiniões a instituição se firma no processo dinâmico da participação política e social, deixando de ser mera transmissora de conhecimento e se transformando em uma ferramenta importante na formação política de todos que dela fazem parte.

Lembrar que ser referencial requer esforço e dedicação, participação e coletividade não são algo fácil de praticar, porém, seu uso cotidiano nos torna mais humanos e muito mais atuantes nas escolhas sociais da vida rotineira. Ser um cidadão consciente é uma arma forte contra o Estado, o Governo e, sobretudo contra a marginalização de não decidir ou optarmos por nossos direitos adquiridos ao longo dos anos.

Para Lück (2010) o processo de liderança no âmbito da gestão educacional é uma característica inerente na qual a figura do gestor escolar mobiliza, orienta e coordena um determinado grupo de pessoas para realizarem uma atuação de excelência no intuito do bem comum, dessa maneira, essas ações devem estar direcionadas na melhoria da qualidade do ensino e aprendizagem dos alunos atendidos pela instituição escolar. O gestor escolar tem um papel proativo no que se refere à implantação de ações inovadoras até ao entusiasmo para criação de expectativas que influenciem na atuação da equipe educacional e nos resultados almejados.

A instituição educacional pode ser classificada como uma organização que socializa comportamentos relacionados às relações sociais entre os sujeitos das mais diversas etnias. Ao entender essa instituição social como organização com mecanismos próprios de atuação é possível assimilar o sentido amplo de seus mecanismos e seus elementos normativos, valores e relações sociais, num emaranhado particular e dinâmico ao longo dos anos. Por essa razão, a importância do Projeto Político 
Pedagógico como organização dos interesses coletivos, construção essa que pertence à busca de autonomia da escola, priorizando atitudes democráticas e comunicativas no meio que está inserida.

O gestor escolar tem papel fundamental na mediação de todos os acontecimentos realizados ou debatidos no âmbito da escola, sua figura deve transmitir aos integrantes da comunidade escolar confiança, segurança e expectativas positivas. Pois, será por meio desse tripé que ele configura sua atuação profissional, almejando sempre o contexto comunicativo no processo de tomada de decisão, fazendo com que esses momentos sejam de caráter participativo e democrático, a construção histórica de uma escola autônoma não é algo fácil e aplicável de um dia para outro, porém, deve ser trilhado de maneira coletiva onde todos que formam a comunidade escolar possam se sentir importantes e ativos nesse processo dinâmico e contínuo.

Para Lück (2010) considera a participação dos professores no processo de tomadas de decisão uma prática positiva para poder escolher ações que possam contribuir no intuito de solucionar os problemas da escola.

A participação efetiva na escola pressupõe que os professores, coletivamente organizados, discutam e analisem a problemática pedagógica que vivenciam em interação com a organização escolar e que, a partir dessa análise, determinem caminhos para superar as dificuldades que julgarem mais carentes de atenção e assumam compromisso com a promoção de transformação nas práticas escolares [...] (LÜCK, 2010; p.33).

Essas análises realizadas pelos professores proporcionam um elo maior entre comunidade escolar e instituição educacional, sendo essa classe de profissionais os que mais mantêm contato com os alunos e pais destes. Os professores engajados nas práticas comunicativas de análise das problemáticas escolares podem facilitar os mecanismos comunicativos entre comunidade escolar e grupo gestor, assim, cabe ao gestor escolar fortalecer seu grupo de professores tornando-os membros ativos e atuantes na construção histórica da identidade escolar. 
Segundo Ferreira (2011) o processo de autonomia não pode ser imposto às instituições escolares, isso seria dicotômico de acordo com o significado do conceito de autonomia. Sendo necessárias as próprias instituições de ensino, por meio de seus órgãos próprios, a experimentarem e expressarem esse sentimento de democracia na busca de priorizar competências que elevem a autonomia a um patamar de construção coletiva e de bem comum a equipe educacional. Essa busca não se resume a um fim e sim a uma construção autônoma das escolas para melhor atenderem seu público com serviços educacionais de qualidade.

Esse espaço pode ser concebido na escola pública, por exemplo, no Conselho Escolar, local de discussão para realização do processo de tomada de decisão. Possibilitando que educadores, funcionários, pais e alunos expressem seus desejos, suas reivindicações em busca da melhoria da estrutura da escola e do ensinoaprendizagem dos alunos. O Conselho Escolar proporciona a aproximação dos centros de decisão das pessoas envolvidas e atuantes, o que facilita a comunicação tanto de caráter vertical de profissionais para profissionais, quanto à comunicação horizontal de professores entre pais e discentes, propiciando a delegação de responsabilidades e o engajamento dos diversos participantes da comunidade educacional. É o órgão máximo de decisão existente dentro do âmbito da escola, podendo proporcionar aproximação da democracia e participação coletiva, gerando assim, autonomia da escola por construção política de seus membros.

Dessa forma, podemos refletir na existência de uma gestão autônoma e democrática no âmbito da instituição de ensino, sendo necessário salientar que a participação coletiva da comunidade escolar no processo de tomada de decisão torna a escola um espaço comunicativo e educativo no aspecto político de formação de uma sociedade. Para Campos (2010) a autonomia pode ser definida como a significativa ruptura dos mecanismos de centralização das tomadas de decisão.

Segunda Gadotti (2010) autonomia é um processo bem mais amplo do que simplesmente a nivelar a sociedade a um patamar e de igualdade, nenhuma sociedade é igual por total e nenhuma comunidade necessita dos mesmos princípios para viver. 
Autonomia não significa uniformização. A autonomia admite a diferença e, por isso, supõe a parceria. Só a igualdade na diferença e a parceria são capazes de criar o novo. Por isso, escola autônoma não significa escola isolada, mas em constante intercâmbio com a sociedade [...] (GADOTTI, 2010; p.46).

Contudo, ao perceber que a escola não se aproxima dessa igualdade pautada nas diferenças, precisamos criar elos de mediação entre gestão, educadores e alunos. Pois, refletindo em nossa constante atuação como profissionais da educação buscarão ampliar os conceitos políticos e, assim, o campo de visualização será maior no que se refere à implantação de uma rotina autônoma e democrática em âmbito educacional. Não podem afastar o processo democrático de nossas atividades rotineiras, porque dessa maneira cairemos na dicotomia de realidade e discurso aplicado.

Segundo Ferreira (2011) o processo da autonomia é formalizado pela negociação de contratos sociais, sendo eles necessários para a formalização de regras sociais que favoreçam a participação coletiva de todos. Portanto, é por meio desse processo anterior que permeia as classificações de cada caso, as competências, os recursos necessários, as estratégias pedagógicas, administrativas e financeiras, almejadas no trajeto destinado a cada uma dessas fases.

O gestor escolar deve entender esses mecanismos fundamentais do processo de autonomia da escola e sua postura deve permear propostas para que venha concretizar práticas voltadas a resolução de problemas existentes no âmbito educacional. Ainda salientado por Ferreira (2011) as escolas devem ter como norte para que ocorra a autonomia os seguintes mecanismos: legitimidade, participação, liderança, qualificação e flexibilidade.

Deve-se entender que esses mecanismos são fundamentais para que ocorra o processo de autonomia dentro da instituição da escolar, portanto, a legitimidade nos auxilia na transparência do processo; participação permite que os sujeitos discutam o mecanismo de toma da decisão; a liderança é um mecanismo favorável no estímulo a 
motivação interna dos membros de uma instituição; qualificação dos profissionais que farão as mediações para que aconteça a tomada de consciência pelos participantes; a flexibilidade no processo de escolha para permanecer um ambiente democrático que vise a análise para que a melhoria da comunidade seja discutida de maneira coletiva e justa (FERREIRA, 2011).

Segundo Adair (2010) explica a importância de listarmos uma sequência de funções para ser exercida por um líder, isso dentro de um contexto ao qual o sujeito encontrase inserido, um exemplo disso seria o seu próprio ambiente de trabalho. Esses mecanismos nos orientam ao desenvolvimento de as ações, portanto, as práticas devem estar norteadas nos seguintes itens: planejar, iniciar (informar a equipe sobre os objetivos e o plano), controlar, apoiar, informar e avaliar.

Dessa forma, ao nos deparar mais uma vez com a questão da postura de um gestor escolar no processo de gerenciamento da instituição escolar, oportunizando a equipe uma melhor ampliação da organização da própria instituição. Garantir que o profissional encontre um apoio eficaz para planejar suas ações, entender os objetivos e necessidades do processo de ensino e aprendizagem dentro da escola, conscientizar os profissionais a formação contínua em âmbito interno, estabelecer um contado direto no processo de tomada de decisão, conhecer os principais problemas de nossa comunidade escolar e 0 ato de avaliar nossas ações ao longo desse percurso.

Para Campos (2010) a educação é um processo que estabelece um equilíbrio entre a conscientização e a interiorização do conhecimento, assim, o sujeito que vivencia precisa de um entendimento de organização para formar um elo de mediação entre conhecimento e universo.

O planejamento assim torna-se essencial a todas as etapas a serem executadas pela instituição escolar, nessa visão da importância da coleta de dados e do planejamento no respectivo ato de educação do sujeito, na atuação do professor e nas metas da instituição é que os gestores devem fomentar mediação entre organização e planejamento do ensino. O gestor deve participar e atuar em todas as etapas do 
processo educativo, desde a coleta de dados até o planejamento e avaliação do processo.

A pedagogia orgânica ao taylorismo ou fordismo tem por finalidade de assistir uma divisão social e técnica do trabalho pela classificação de espaços existentes entre sujeitos envolvidos no trajeto intelectual e instrumental, em relações a atuação profissional bem definida e compartilhada determinando funções entre os membros integrantes e organizando o trabalho da instituição educacional.

Isso contribui no intuito da formação da equipe de trabalho e seus papéis de atuação ao longo do processo educativo, o gestor deve ter uma postura de líder no percurso das tomadas de decisões que favoreçam positivamente a instituição educacional. Se os membros da escola encontrar respeito na atuação da figura do gestor o trabalho desenvolvido por essa instituição de ensino será algo pautado no reflexo da democracia participativa e atuação ativa de todos que compõem a unidade escolar (FERREIRA, 2011).

O gestor deve ser um profissional atuante, sendo sua figura de um líder onde os outros profissionais a educação encontre nele apoio, segurança, respeito, lealdade, solidariedade, humildade, profissionalismo, equidade, humanização, criatividade, habilidade de resolver problemas e acima de tudo tenha-o como um exemplo de profissional atuante.

O profissional da gestão tem que compreender da história da educação, dos mecanismos de ensino, das metodologias alternativas, do processo de gerenciamento, das normas do seu município e estado, assim como as normativas federais para a educação, fazer a mediação de tomadas de decisão e da vivência educacional.

Ser gestor é além de ser líder, profissional e educador, é acima de tudo ser humano. Saber que sua atuação deve estar pautado na humanização da habilidade de lidar com pessoas de diferentes etnias e conhecimentos, conhecer seu espaço de atuação 
para poder criar metas e garantir a comunidade atendida pelo serviço educacional qualidade no processo ensino e aprendizagem.

Assim, a gestão escolar entendida como democrática e participativa é uma execução de caráter coletivo que necessita da participação de todos que formam a comunidade escolar e o direcionamento de objetivos comuns e, por outra instância, depende das habilidades individuais e das respectivas implementações coordenadas e organizadas por esse modelo de gestão.

\section{A GESTÃO ESCOLAR PARTICIPATIVA SOB A ÓTICA DOS GESTORES E DOCENTES}

Com o intuito de conduz a uma melhor compreensão dos leitores, considera-se importante relatar como foi tratada a transcrição dos dados, apresentação e análise do material coletado nas entrevistas. Para a apresentação dos dados, optou-se por agrupar as respostas coletadas em Eixos Temáticos e Tópicos de Análise. Assim, todas as respostas obtidas nas entrevistas foram enumeradas, mantendo-se o anonimato dos indivíduos envolvidos na pesquisa. Cada profissional da educação foi reconhecido por sua função de atuação: D1 - Diretor 1; D2 - Diretor 2, C1 Coordenador 1; P1 - Professor 1; P2 - Professor 2 e P3 -Professor 3.

Desta maneira este tópico abordará a discussão e análise dos referidos eixos temáticos que ajudarão na busca de se compreender o processo da gestão participativa dentro de nossas escolas. Os eixos temáticos foram organizados e analisados levando-se em consideração os dados coletados nas entrevistas respondidos pelos profissionais da educação. Portanto, as respostas estão dispostas de acordo com os tópicos de análise.

No Eixo Temático 1 foram atribuídos referências as características pessoas dos profissionais da educação que participaram da pesquisa, assim, poderíamos traçar um perfil dos indivíduos que atuariam no processo de tomada de decisão, na comunicação e no gerenciamento dos recursos destinados a esta unidade de ensino. 
Portanto, dos entrevistados $100 \%$ pertença a rede pública de ensino do município de Fortaleza-Ce, dessa população $83,33 \%$ é do sexo feminino e $16,66 \%$ do sexo masculino. Enquanto a modalidade 16,66\% pertencia à educação infantil, 33,33\% ao ensino fundamental e 50\% pertence à gestão financeira e pedagógica, ainda referindo ao quesito escolaridade do educador e gestor, temos $16,66 \%$ do quadro cursando superior na modalidade normal e $83,33 \%$ com superior completo.

Um dos fatores que se deve levar em consideração é a formação ou tempo de experiência desses profissionais, isso poderá implicar positivamente ou negativamente no processo de tomada de decisão, portanto, dos entrevistados $50 \%$ possuía de 5 a 10 anos de docência, e $50 \%$ da amostra da população da pesquisa possuía de 10 a 15 anos de docência.

Essa população também se encontrava entre a faixa etária de $33,33 \%$ entre os 31 a 35 anos de idade, $16,66 \%$ entre 36 a 40 anos e $50 \%$ mais de 41 anos respectivamente. Esses profissionais trabalhavam nos seguintes turnos, manhã e tarde $66,66 \%$ e manhã, tarde e noite 33,33\%. Acrescentando a merecimento aos vários papéis que acabamos por assumir no cotidiano foi acrescido o estado civil dos entrevistados, assim, 33,33\% da amostra declarou ser solteira e $66,66 \%$ dela casada.

Atualmente no Século XXI vivencia-se uma inserção maior da mulher no mercado de trabalho, assim, a mulher ganha mais espaço no ambiente profissional e, dessa forma, os papeis familiares começam a serem modificados. Isso fica claro também nessa pequena amostragem onde o público entrevistado feminino representa $83,33 \%$ da população pesquisada.

O magistério representado pela população feminina nos revela uma dupla função dessa população feminina, pensando na função de atuação profissional, familiar e social. Essa amostragem tem papel de mãe, profissional e esposa, dessa maneira, esse tripé representa uma sobrecarga à mulher, tornando muitas vezes menos produtiva e mais susceptível ao processo de adoecimento. 
A figura masculina também tem crescido na profissão do magistério, apesar de revelar maior a presença das mulheres na educação infantil e séries iniciais. O nível de formação dos educadores municipais é indicado por um grupo bem maior de educadores como curso superior, isso fica claro na pesquisa, apesar da amostragem ter sido pequena, foram diagnosticados que $83,33 \%$ da população pesquisa já possuíam o nível superior atendendo o Art. 62 da Lei de Diretrizes e Bases da Educação - Lei № 9.394/96.

No eixo temático 2 pode-se observar a fala dos gestores e suas respectivas visões em relação ao processo de gerenciamento da unidade escolar, o que eles entendem por gestão participativa, e como isso poderia acontecer na práxis educacional. Assim, depois de uma conversa com os gestores de uma escola pública de Fortaleza podese analisar a realidade das escolas no quesito do gerenciamento educacional.

Questionou-se a respeito do papel do gestor escolar ressaltando que a escola existe por ter em sua essência uma finalidade social, portanto, o que esses administradores internos das unidades escolares podem fazer nesse caminho de democratização e oferta de um serviço de qualidade.

Administrar financeiramente sem esquecer o pedagógico, a escola que pedagogicamente não é bem gerida, seus objetivos jamais serão alcançados, então o gestor educacional tem que ter essa visão: D2.

Portando, esse percurso se constrói ao longo do processo administrativo da unidade escolar, o gestor ao passo que gerencia apreende quais mecanismos é útil e quais podem ser aprimorados para que aconteça uma real autonomia da instituição educacional. Assim, espera-se que a postura da gestão escolar seja algo dinâmico e democrático no que refere as escolhas e as tomadas de decisões.

Manter a instituição em bom funcionamento, isso refere às questões pedagógicas, administrativas, recursos humanos e financeiros. Toda e qualquer gestão escolar deve ser uma espécie de coluna para sustentar a escola e fornecer os elementos que ela precisa para sua sobrevivência 
diária, podendo estimular tanto os que por ela são assistidos como aqueles que nela prestam seus serviços. A instituição deve ser vista holisticamente, assim, ela estará mais respaldada para prestar um serviço de excelência: D1.

O papel do gestor é proporcionar ambientes dos mais variados possíveis no intuito de garantir a participação de toda comunidade escolar de maneira democrática e participativa, visando uma escola autônoma no que se refere às decisões para melhoramento e inclusão da disseminação de sua cultura regional.

Bem, o gestor para desempenhar bem o seu papel tem que primeiro saber o que é democracia. Pois no âmbito escolar hoje não atribuir responsabilidades para o grupo e sabermos que cada membro tem sua responsabilidade, então assim, conseguiremos ter uma gestão participativa: D2.

Assim, compreende-se que o processo de tomada de decisão em uma instituição seja ela qual for, é bem mais amplo que simplesmente decidir qual estratégia usar. Esse mecanismo de escolha exige do gestor, liderança e comunicação para mediar e saber interligar os conhecimentos dos profissionais que estão envolvidos e sensibilizados na resolução dos problemas em âmbito interno.

Sabemos que toda e qualquer decisão tem que ser justa, pois, não podemos prejudicar uma comunidade, pois buscamos atingir metas e dentre as ações temos objetivos, então sempre estamos correndo sérios riscos, porém, decisões são fundamentais e enérgicas para que alcancemos nossos objetivos: D2.

$\mathrm{Na}$ sequência das perguntas argumentadas aos gestores foram referidos os pontos fortes e fracos no contexto educacional segundo o D2:

Eu diria que numa instituição escolar existem erros e acertos, pois, quando o objetivo almejado é alcançado é todo o grupo, quando não acontece da culpa ser do gestor que não tem tomada de decisões e que 
na verdade toda a comunidade tem sua (co) participação, seja nos erros ou nos acertos, temos que salientar que o objetivo maior da escola é o aprendizado do aluno.

Dessa maneira, são claro que os focos das discussões devem permear o âmbito do processo ensino e aprendizagem de nossos educandos, todas as melhorias devem ser em prol de propiciar conforto, acessibilidade e estímulo a motivação de nossa comunidade escolar. A escola deve ser a "porta" de entrada do cidadão ao universo sociocultural como suas facetas no ciclo da vida de um povo.

A interação com o núcleo gestor nos proporciona uma ampla visão no que competente ao processo de gerenciamento de uma instituição de ensino, assim, quem está no entorno desse percurso poderá entender como a escola é administrada em caráter gerencial, financeiro e pedagógico.

Esse percurso das colheitas de dados realizadas nas falas dos educadores D1 e D2, nos mostra paralelamente os fatores que estão envolvidos no ciclo gestacional de uma instituição educacional, vivenciando de maneira real as discussões a respeito do papel do gestor educacional, sua postura, sua relação e interação com a comunidade escolar, comunicação no processo de mediação e a liderança no processo de tomada de decisões.

Serão escolhidas algumas questões para ampliar melhor essas discussões e as que serão mais pertinentes para que se possa compreender mais adequadamente o processo de gerenciamento de uma instituição de ensino, portanto, tanto os discentes do magistério como os profissionais atuantes e os gestores poderão refletir para poder entender como ocorre o processo gestacional de uma instituição de ensino e quais mecanismos precisam nos aliar para assimilar de forma democrática esse percurso.

O gestor é um indivíduo que está inserido em todos os momentos da escola, desde o que compete ao pedagógico e os quesitos administrativos tidos como organização documental, assim, como os recursos disponíveis para que ocorra a manutenção da instituição. 
Nas falas do Eixo Temática - 2 percebem-se a importância de a instituição escolar trabalhar em um direcionamento fundamentado na excelência, contudo percebe-se que muitos mitos e conflitos são gerados nessa instituição, contudo ela precise enfrentar e assumir o posto de democracia e participação coletiva de forma inclusiva.

Administrar financeiramente sem esquecer o pedagógico, a escola que pedagogicamente não é bem gerida, seus objetivos jamais serão alcançados, então o gestor educacional tem que ter essa visão: D2.

O gestor além de mediar esses mecanismos importantes para o bom funcionamento da escola, como o gerenciamento de pessoas, de recursos matérias e financeiros, de estratégias tanto dos planos como dos projetos educacionais, administrar e registrar todos os documentos realizados pela escola - ata, livro de registro, livro de ponto, declarações, histórico e certificações dentre outros.

A identidade desse profissional vai se construindo ao longo da história de sua atuação, portanto, sua prática estará pautada no gerenciamento democrático do processo de ensino e aprendizagem da instituição educacional, assim claro como todas as formas de registro documental dessa unidade de ensino.

No que se refere às melhorias e as mudanças no âmbito educacional com que venham favorecer a política de democratização da instituição educacional, sendo o gestor um fundamentador desse percurso de participação da comunidade e dos colegiados que formam o ambiente educacional. Tendo a missão de garantir transparência nos percursos administrativos e financeiros da instituição de ensino, sendo assim o mesmo deve contribuir:

Nunca esquecer que somos um grupo e que numa gestão democrática toda tomada de decisão tem que haver a participação da comunidade escolar e que o gestor sozinho não conseguirá nenhum objetivo, principalmente construir uma aprendizagem de qualidade na escola: D1.

O importante para se compreender mais além da visão dos que se encontram na gestão propriamente dita, ouvir de maneira analítica os que estão nesse emaranhado 
e participam diretamente de todos os mecanismos de mudanças acontecidas na escola, portanto, as observações dos educadores nos auxiliarão no trajeto de entender o que a gestão educacional vem realizando para manter e garantir uma escola como uma instituição que tenha um padrão de excelência no processo de ensino e aprendizagem.

Dessa maneira, a questão debatida aqui será a respeito do processo gerencial existentes nas unidades de ensino, assim, como o perfil desses gestores no que compete à tomada de decisão e a mediação desse mecanismo em âmbito interno da instituição. Entendendo que essa instituição deva ter sua identidade construída de forma coletiva e debatida, sendo sua proposta pedagógica um documento que direcione a ação escolar para almejar os fins do processo de ensino e aprendizagem.

Por meio dos dados coletados ao longo das entrevistas, verifica-se que os profissionais da educação, compreendam plenamente essa construção de caráter coletivo e democrático, os mecanismos educacionais existentes na escola e o impacto em que seu próprio trabalho pode realizar na construção da autonomia dos estabelecimentos educacionais. Porém na prática temos sofrido muito para que a transparência do processo de gerenciamento aconteça de maneira coerente, democrática e participativa de forma holística.

Quando se questiona ao entrevistado P1 sobre o modelo de gestão atual ele refere às reuniões para tomada de decisões em âmbito pedagógico, o que diferentemente nos levanta vários questionamentos a respeito da democracia e transparência do processo de tomada de decisão. Sendo essa estratégia de coletividade uma forma de participação e democracia nos mecanismos comunicativos a fim de auxiliar os gestores na escolha das melhores sugestões que venham aprimorar o ambiente escolar, fortalecendo e garantindo um bom espaço educativo no quesito de serviços de excelência.

Parcialmente. As decisões em relação às atividades pedagógicas são tomadas de forma coletiva, todos podem opinar quanto a datas, temas e formas da realização dos projetos. Professores e gestão se reúnem para 
tal fim, porém não há essa reunião quanto à aplicação dos recursos financeiros recebido pela instituição, atualmente pão acontece nenhuma reunião com esse fim: P1.

Outro quesito importante é como o processo de tomada de decisão é encarado pelos gestores escolares, as decisões devem ser sugeridas em grupo, se possível com um representante de cada membro da comunidade escolar. O sinônimo de instituição democrática é instituição transparente, isso condiz com a implantação de um universo democrático e coeso nas tomadas de decisões, pois, a comunicação é um prérequisito para a manutenção de uma liderança ativa e compromissada com o ensino e aprendizagem.

Os gestores escolares em muitas escolas fazem uso de sua "autoridade" ou "abuso de autoridade", o que acontece é que o que prevalece sempre é a sua ideia, ou seja, sempre é o que dá a palavra final, não existem os elos de troca de informação entre gestores e educadores: P2.

Considerando a concepção da gestão escolar democrática e participativa nas opiniões sobre as decisões a serem tomadas para o melhoramento da estrutura, do atendimento ou serviços, dos recursos materiais e manutenção dessa instituição. Dessa forma, os elementos que possibilitam a mobilização de pessoas, organizadas coletivamente, como condição básica e fundamental da qualidade de ensino e transformação da construção da identidade da instituição, das pessoas nelas inseridas e da educação por ela ofertada a população.

A gestão participativa e democrática é algo que inclui não só a participação da população, mas a formação de consciência acerca das prioridades reais e como podemos melhor trabalhar a solução de problemas, mediando e avaliando esse processo a cada instante para proporcionarmos engajamento na autonomia do profissional.

Gestão democrática e participativa ocorre quando todos participam de forma articulada da tomada de decisão quanto aos recursos humanos, 
burocráticos e financeiro com o objetivo de melhorar a essência da educação. Para implantá-la é preciso abrir espaços para que todos participem de forma consciente e igualitária: P1.

Assim, é necessário que as escolas abram suas partas para termos o privilégio de estarmos inseridos no processo de tomada de decisão, contudo, a crítica é essencial no modelo de gestão educacional que vivenciamos nesses meados do início do Século XXI, portanto, os educadores devem ter consciência que a construção de sua identidade autônoma é contínua e, assim, é uma trajetória que só se constrói coletivamente.

Não, há avanços, que são percebidos através do advento de alguns profissionais que estão compondo uma nova proposta de gestão, percebe-se uma descentralização das ideias e opiniões, relacionado à parte pedagógico, ao tempo do aluno e a recursos da instituição, ainda a pontos que precisam ser melhorados e aplicados a partir de decisões tomadas por todos os segmentos representativos da instituição: P3.

Um dos maiores desafios dos gestores está vinculado à organização do espaço educacional, assim, como a formação e fortalecimento das equipes existentes no universo escolar.

A pesquisa constata que muitas mudanças ainda precisam acontecer para que a escolar venha ser uma instituição autônoma e democrática. Assim, as questões pedagógicas ficam vinculadas ao coordenador pedagógico, contudo o gestor educacional deve estar inserido em todo o processo de tomada de decisão, pois, desde o cunho pedagógico ao financeiro a presença desse profissional é de fundamental importância.

Portanto, esse contexto nos proporciona pensar a respeito da postura do gestor em frente às decisões realizadas na instituição de ensino, esse profissional deve ser o elo de mediação entre as propostas educacionais, ambiente externo e ambiente interno. Suas intervenções serão de grande valia para que a escola seja "palco" de um 
universo democrático, onde a participação seja elevada como ferramenta fundamental para que ocorra o melhoramento da estrutura da instituição, dos mecanismos metodológicos e assim como dos serviços prestados a sociedade.

\section{MÉTODO DA PESQUISA: UMA REFLEXÃO CIENTÍFICA A METODOLOGIA UTILIZADA}

Portanto, o processo de educar perpassa de uma implementação social simplesmente, uma conscientização pessoal acerca do mecanismo de humanização pertinente em nosso convívio social atual. Assim, no próximo tópico estaremos debatendo sobre a real postura do educador na figura do gestor escolar, a opinião de profissionais que trabalham com educação nos ajudará a compreender como a gestão deve atuar e como é sua real atuação nos dias atuais.

O presente trabalho optou por utilizar a metodologia da pesquisa experimental qualitativa por ser uma trajetória que oportuniza aos profissionais da educação e estudantes da área a conhecer o assunto da gestão escolar e fazer descobertas sobre $o$ ato de gerenciamento de uma instituição de ensino. Portanto, os discentes e profissionais da educação poderão encontrar novos significados sobre o tema em questão, debater e esclarecer fidedignamente o que já se sabe,reafirmando o conhecimento como algo não-acabado, ou seja, como uma construção que se constrói ao longo dos anos, tornando o processo educativo em quaisquer instâncias um momento único e dinâmico (KÖCHE, 2009).

Para a elaboração de uma pesquisa científica de caráter qualitativo é necessário a confrontação dos dados coletados ao longo da pesquisa, evidências observadas, informações sobre determinado assunto e saberes teóricos a respeito do problema em questão. Esse emaranhado de mecanismos para a colheita dos dados nos revela saberes antes não conhecido ou mesmo a veracidade de outros já existentes, nesse esforço de construir os saberes científicos que favorecerão para a análise de possíveis soluções para os problemas da realidade educacional em discussão. 
A pesquisa foi sistematizada e organizada no segundo semestre de 2019 , em uma escola do município de Fortaleza, capital de estado do Ceará, a instituição de ensino oferece serviços às seguintes modalidades de ensino: Educação Infantil, Ensino Fundamental (do $1^{\circ}$ ao $5^{\circ}$ ano). A comunidade atendida por esta instituição de ensino é de um bairro da periferia de Fortaleza, comunidade carente por assistência médica, por saneamento básico e inúmeros problemas de ordem social e socioeconômica.

Os participantes deste trabalho foram escolhidos por fazer pertencerem a uma unidade de ensino da periferia de Fortaleza-CE, onde houve uma conversa inicial apresentando os objetivos da pesquisa e explicando a importância da reflexão a nossa atuação no processo de tomada de decisão dentro de nossas escolas. Assim, os critérios de seleção dos gestores e professores, neste trabalho, foram realizados de maneira aleatória tendo como direcionamento pertencer a uma escola localizada na periferia e com inúmeros problemas em sua essência, portanto, o critério primordial é o de ser professor da rede municipal de educação de Fortaleza-CE, está inserido nas reuniões, caso se houver, para resolver ou solucionar metas na buscar de sanar com essas dificuldades que assolam a instituição educacional.

Para enriquecer os assuntos aqui explorados e também para um bom entendimento do leitor, utilizou-se uma amostra de sujeitos (entrevista) como representação do tema, orientando a percepção do contexto atual de educação, permitindo representar a informação de maneira exploratória, por meio de uma sistemática de categorias, produto das intervenções realizadas ao longo do percurso da pesquisa em questão.

As questões utilizadas na entrevista baseiam-se nos principais momentos que a instituição escolar pode tornar-se democrática e participativa. Assim, essas poderão servir como análise a reflexão constante que o gestor e os membros envolvidos no processo de tomada de decisão devem pensar ou repensar sempre. $O$ ato de discutir e agir pela melhoria da qualidade da instituição educacional, nos permite a oportunidade de formar uma gestão pública de excelência no âmbito democrático do processo dinâmico da sociedade globalizada, cuja estamos inseridos. 


\section{CONSIDERAÇÕES FINAIS}

De acordo com os objetivos almejados nesta pesquisa analisa-se que a gestão escolar enfrenta o desafio de ofertar uma educação política de qualidade no processo de tomada de decisão em âmbito interno. O território brasileiro elegeu a gestão democrática como um dos mecanismos para a construção de uma cidadania autônoma, capaz de tomar decisões individuais e coletivas, articulando-se para compreensão da realidade social.

A gestão educacional democrática e participativa é um mecanismo de democratização da instituição educacional e da mediação existentes nas relações sociais com o contexto histórico que se experimenta contemporaneamente. É evidente que esse modelo de gestão escolar democrática, vem sendo organizada e construída na rotina da instituição educacional, na figura do gestor, um dos líderes responsáveis para a criação e manutenção de processos de tomadas de decisões, haja vista que esse percurso de discussão é um espaço democrático.

Essa pesquisa proporcionou a análise da postura dos gestores no processo de tomada de decisão em âmbito interno e os elos de mediações que são conduzidas por essa figura do gestor como um líder que "filtre" as opiniões no intuito de escolher as melhores condutas.

O profissional da educação passa pelo processo de internalização da autonomia das escolhas internas e externa acerca do melhoramento da instituição educacional e do processo ensino e aprendizagem. A entrevista proporcionou um olhar aguçado acerca dos mecanismos utilizados no âmbito escolar para solucionarmos problemas graves existentes ou mesmo fazer reparos que venham amenizar as dificuldades da instituição educacional.

$\mathrm{Na}$ análise dos relatos foi visto ou constatado que os profissionais da educação querem mudanças no que diz respeito ao processo de gerenciamento da unidade escolar. E que os gestores podem estimular positivamente ou negativamente na motivação dos profissionais da instituição escolar como um todo. 
Portanto, ao busca-se a análise da importância do papel do gestor no direcionamento da práxis educacional a caráter democrático e participativo, esse mecanismo como elemento fundamental, na melhoria progressiva da instituição no território brasileiro, assim, observou que se precisa de um estudo mais aprofundado sobre a implantação da democracia participativa na escola para que o processo de tomada de decisão seja algo dinâmico e coletivo de maneira generalizada.

Analisa-se ainda, que os professores querem esse processo de tomada de decisão esclarecido de forma compromissada com a promoção de mudanças na estrutura física, curricular, organizacional ou mesmo social das práticas educacionais. A gestão escolar democrática e participativa deve oferecer aos profissionais da educação, assim como toda comunidade escolar, o verdadeiro desafio de perceber e decidir os mecanismos de igualdade e oportunidades para a significância da democracia no processo de tomada de decisão, gerando dessa maneira igualdade nas necessidades de todos que são desiguais em suas reais necessidades.

Em suma, a viabilidade desta rotina do gerenciamento da escola, apenas será viável, quando se supera as práticas autoritárias que permeiam as rotinas educativas, e estas serem representadas por mecanismos de participação coletiva, que favoreça o desenvolvimento humano oferecendo novas possibilidades de oportunidades acerca das ações educativas, fazendo um paralelo ao papel do gestor como empreendedor e gerenciador do processo de ensino do nosso estado.

Assim, conseguiu-se de maneira suscita explorar os objetivos almejados desta pesquisa, utilizou-se de uma metodologia que envolvesse os "atores" inseridos em âmbito institucional interno no processo de gerenciamento e tomada de decisão. No desfecho da pesquisa observou-se que o problema foi respondido de maneira clara, pois, tanto os gestores como os educadores sabiam o que significava uma gestão participativa e democrática, contudo, ficou muito nítido que esse modelo ainda é um tópico a ser alcançado pelos nossos gestores educacionais.

Essa pesquisa não finda esse assunto, mas sugere um salto no quesito de implementação de uma gestão democrática e participativa, como a comunidade 
escolar ver esse processo de tomada de decisão, até que ponto as escolas são transparentes nas suas prestações de contas e o mais importante que tipo de cidadão está sendo formado por estas instituições de ensino respectivamente. Portanto, além de alcançar as metas traçadas por este estudo, estamos a propiciar novos rumos a ser estudados e analisados, a pesquisa não finda com um final conclusivo, ela tem o intuito de gerar uma reflexão e mudança na postura dos profissionais que dela se apoderam.

\section{REFERÊNCIAS}

ADAIR, John. Liderança e motivação: a regra do meio a meio e os oito princípios fundamentais para motivar os outros. -São Paulo: Clio Editora, 2010.

BRASIL. Conselho Escolar, gestão democrática da educação e escolha do diretor. Brasília/DF. v. 5, 2005.

CAMPOS, Casimiro de Medeiros. Gestão escolar e docência. - São Paulo: Paulinas, 2010.

FERREIRA, Naura Syria Carapeto (Org.). Gestão democrática da educação: atuais tendências, novos desafios. - 7. ed. - São Paulo: Cortez, 2011.

GADOTTI, Moacir. Escola cidadã. - 13. Ed. - São Paulo: Cortez, 2010.

LÜCK, Heloísa. Liderança em gestão escolar. 6. ed. - Petrópolis, RJ: Vozes, 2010.

A gestão participativa na escola. - Petrópolis, RJ: Vozes, 2017a. Série Cadernos de Gestão

. Gestão educacional: uma questão paradigmática. - Petrópolis, RJ: Vozes, 2017b. Série: Cadernos de Gestão

OLIVEIRA, Maria Auxiliadora Monteiro (Organizadora). Gestão educacional: novos olhares, novas abordagens. 7. ed. - Petrópolis, RJ: Vozes, 2010. 
PAIVA, Francisco Jailson de. Gestão participativa: impactos sobre a produtividade organizacional. - 1. ed. - Curitiba: Appris, 2016.

Enviado: Agosto, 2019.

Aprovado: Janeiro, 2020. 